\title{
Kajian Kebutuhan Belajar Klien dengan Penyakit Jantung Koroner
}

\author{
Rega Dwi Putri, Aan Nur'aeni, Valentina Belinda \\ Faculty of Nursing, Universitas Padjadjaran \\ Email : regadwiputri@gmail.com
}

\begin{abstract}
Abstrak
Penyakit Jantung Koroner (PJK) merupakan penyakit yang harus dikontrol seumur hidup. Hal ini membutuhkan kepatuhan dari penderitanya, salah satu cara untuk meningkatkan kepatuhan adalah melalui pendidikan kesehatan, namun demikian pendidikan kesehatan seringkali kurang efektif karena tidak melalui hasil kajian kebutuhan terlebih dahulu. Penelitian ini bertujuan mengidentifikasi kebutuhan belajar klien dengan PJK di salah satu rumah sakit di Kota Bandung. Metode dalam penelitian ini deskriptif kuantitatif. Sampel dalam penelitian ini adalah klien PJK yang menjalani rawat inap dan rawat jalan. Teknik sampling dilakukan dengan consecutive sampling, pengambilan data dilakukan selama 30 hari dan didapatkan sebanyak 105 responden. Pengumpulan data menggunakan instrumen $A$ Turkish Version of the Cardiac Patients Learning Needs Inventory (TR-CPLNI). Analisis data menggunakan mean dan distribusi frekuensi dengan persentase. Hasil penelitian menunjukkan bahwa terdapat lima kebutuhan belajar dengan mean tertinggi, yaitu kebutuhan tentang anatomi dan fisiologi jantung $(4,41 \pm 0,71)$; kebutuhan tentang informasi obat $(4,34 \pm 0,76)$; kebutuhan informasi tentang gaya hidup $(4,30 \pm 0,77)$; kebutuhan tentang informasi diet $(4,19 \pm 0,82)$; serta kebutuhan tentang manajemen gejala $(4,08 \pm 0,93)$, dan kelima kebutuhan ini masuk kedalam kategori kebutuhan belajar yang penting bagi pasien PJK. Berdasarkan hasil penelitian dapat disimpulkan bahwa seluruh kebutuhan belajar pasien PJK berdasarkan persepsi pasien adalah penting, termasuk didalamnya kebutuhan tentang informasi anatomi dan fisiologi jantung yang menjadi kebutuhan belajar yang paling penting dirasakan oleh pasien PJK. Tenaga kesehatan perlu memenuhi dan menyusun program pendidikan kesehatan bagi pasien PJK, meliputi seluruh kebutuhan belajar pasien ini.
\end{abstract}

Kata kunci: Kajian, kebutuhan belajar, penyakit jantung koroner.

\section{Study of The Learning Needs for Clients with Coronary Heart Disease}

\begin{abstract}
Coronary Heart Disease (CHD) is a disease that must be controlled. This requires adherence from the sufferer, and one of efforts improving adherence can be done through health education. However, health education is often less effective because it is not based on the needs assessment. The purpose of the study was identified the learning needs of clients with CHD in one hospital in Bandung. The method of the research used quantitative descriptive method. The samples was patients with CAD who undergone inpatient and outpatient. The sampling technique used consecutive sampling, data retrieval for 30 days and obtained of 105 respondents. The data was collected by A Turkish Version of the Cardiac Patients Learning Needs Inventory (TR-CPLNI) instrument. Data was analized using mean and frequency distribution with percentage. The results showed that there were five learning needs with the highest mean, namely the need for anatomy and cardiac physiology $(4.41 \pm 0.71)$; the need for drug information (4.34 \pm 0.76$)$; need for information about lifestyle $(4.30 \pm 0.77)$; the need for dietary information (4.19 \pm 0.82$)$; and the need for symptom management (4.08 \pm 0.93$)$, and these needs were in important category according to patients perception. Based on the results of the study it can be concluded that all the learning needs of CHD patients based on patient perception was important and the need for information on cardiac anatomy and physiology became the most important learning need felt by CHD patients. Health workers need to meet and develop health education programs for CHD patients covering all the learning needs of these patients.
\end{abstract}

Keywords: Coronary heart disease, learning needs. 
Rega Dwi Putri : Kajian Kebutuhan Belajar Klien dengan Penyakit Jantung Koroner

\section{Pendahuluan}

Penyakitkardiovaskularmerupakan penyebab kematian tertinggi. Secara global 17,5 juta penduduk meninggal karena penyakit jantung. Kematian akibat penyakit jantung sebanyak 80 persen di negara berpendapatan rendah dan menengah (Delima et al., 2009). Organisasi Kesehatan Dunia pun menyatakan bahwa sejak tahun 1990, lebih banyak orang di seluruh dunia meninggal karena Penyakit Jantung Koroner (PJK) dibanding penyebab lainnya (Cole, Smith, Hart, \& Cupples, 2011). Prevalensi PJK di Indonesia tahun 2013 berdasarkan diagnosis dokter sekitar 883.447 orang dan diperkirakan jumlah terbanyak terdapat di Provinsi Jawa Barat sebanyak 160.812 orang (Kemenkes RI, 2014). Data insidensi PJK sangat tinggi didapatkan medical record dari rumah sakit rujukan terbanyak di Kota Bandung bahwa jumlah klien rawat jalan tahun 2015 saja mencapai 15.639 kasus.

PJK merupakan akibat adanya penyumbatan pembuluh darah koroner (Uysal \& Enç, 2012). Gejala umum yang penderita PJK alami ketika serangan akut adalah nyeri dada yang kebanyakan sebagai penyebab kekambuhan (Haasenritter et al., 2012). Penanganan pada fase akut bertujuan menurunkan angka mortalitas. American Heart Association (AHA) merekomendasikan beberapa strategi manajemen nyeri, yaitu pemberian morfin sulfat dan oksigen (Ignatavicius \& Workman, 2013).

Penanganan PJK pasca serangan akut adalah dengan melakukan pencegahan sekunder berupa perubahan gaya hidup dan rehabilitasi pasca serangan jantung. Penanganan PJK pasca serangan akut bertujuan menurunkan kejadian serangan berulang (Kemenkes RI, 2011 dalam Indrawati, 2012). Tujuan pencegahan sekunder merupakan salah suatu upaya yang dapat dilakukan klien untuk mencegah perburukan kondisi jantungnya (Rilantono, 2012).

Salah satu faktor berulangnya klien terkena serangan jantung adalah akibat ketidakmampuan klien PJK dalam melakukan pencegahan sekunder (Indrawati, 2012). Informasi obat merupakan salah satu kebutuhan belajar yang harus disampaikan kepada klien, sehingga klien mampu meakukan tindakan pencegahan sekunder terkait obat, namun dalam kenyataan klien PJK belum mampu melakukan tindakan pencegahan sekunder terkait konsumsi obat yang tidak digunakan sesuai aturan. Hal tersebut merupakan salah satu penyebab kekambuhan pada klien PJK (Handayani, 2013). Pengendalian dalam melakukan tindakan pencegahan sekunder tidak hanya terkait obat dan perubahan gaya hidup, namun didalamnya juga terdapat pengendalian stres. Komalasari (2013) dalam penelitiannya menyatakan bahwa persepsi negatif terhadap penyakit masih menggangu pikiran klien. Klien lebih takut dan cemas jikalau secara tiba-tiba mereka mengalami serangan jantung dan nyeri hebat yang pernah dirasakan datang kembali. Selain itu, dalam hasil penelitian Haryati (2009) yang dilakukan di ruang intensif di salah satu Rumah Sakit di Jawa Barat bahwa klien dengan infark miokard akut $100 \%$ mengalami stres emosional. Klien yang mengalami stres emosional dapat memengaruhi kesehatannya dan memicu serangan berulang yang dapat menjadi salah satu potensial penyebab kekambuhan. Sehingga klien harus mengetahui kebutuhan belajar tentang informasi faktor psikologis.

Khan et al. (2006) mengemukakan bahwa sebagian besar pasien yang mengalami serangan jantung kurang pengetahuan tentang gejala akan terjadinya serangan jantung, sehingga terlambat dibawa kerumah sakit bahkan menyebabkan kematian mendadak. Hasil penelitiannya didapatkan bahwa $68 \%$ pasien memiliki pengetahuan yang rendah tentang faktor risiko penyebab PJK (Wahyuni, Nurrachmah, \& Gayatri, 2012). Upaya perawat untuk menekan prevalensi kekambuhan adalah meningkatkan kesadaran klien untuk mengetahui dan melakukan manajemen preventif melalui pendidikan (Indrawati, 2012). Perawat harus memberikan pendidikan bagi klien sebagai metode dukungan rutin dan tindak lanjut perawatan dengan mempertimbangkan kebutuhan belajar klien sebagai upaya meningkatkan kualitas hidup klien PJK (Valiee, Razavi, Aghajani, \& Bashiri, 2016).

Edukasi harus diberikan kepada klien 
Rega Dwi Putri : Kajian Kebutuhan Belajar Klien dengan Penyakit Jantung Koroner

dengan mempertimbangkan dan mengkaji kebutuhan utamanya, sehingga klien menjadi tahu serta dapat mengontrol faktor resiko kekambuhan terkait PJK. Selain itu, efek dari ketepatan edukasi sesuai kebutuhan belajar klien adalah dapat menekan angka risiko kekambuhan. Terdapat hubungan yang bermakna antara pengetahuan dengan kemampuan melakukan pencegahan sekunder (Indrawati, 2014). Pengetahuan klien terhadap penyakitnya juga dapat membantu untuk mengatasi efek penyakitnya dengan lebih baik (Jaarsma et al., 2000 dalam Galdeano \& Rossi, 2010).

Hasil wawancara yang dilakukan peneliti dengan salah satu perawat di salah satu rumah sakit di Kota Bandung mendapatkan informasi bahwa form pengkajian edukasi sudah ada. Namun, kelemahan dari form pengkajian edukasi yang ada hanya dalam bentuk pertanyaan secara umum tidak mendeskripsikan satu-satu item kebutuhan pada klien PJK dan form tersebut digunakan di segala ruangan, sehingga tidak secara spesifik khusus untuk mengkaji kebutuhan belajar pasien jantung.

Berbagai macam tipe kebutuhan setiap klien penting diketahui oleh perawat agar nantinya apa yang diberikan dapat berjalan sesuai yang diharapkan. Hal yang diperlukan untuk pendidikan yang efektif yaitu berupa identifikasi kebutuhan pembelajaran utama yang klien butuhkan. Sehingga pemberian edukasi dapat tersampaikan maksimal dan tepat sasaran sesuai kebutuhan klien. Maka dengan ini peneliti merasa perlu melakukan penelitian mengenai kajian kebutuhan belajar pada klien dengan PJK.

\section{Metode Penelitian}

Rancangan penelitian yang digunakan adalah deskriptif kuantitatif. Variabel yang diteliti adalah kebutuhan belajar pasien dengan PJK. Sampel penelitian berjumlah 105 responden dipilih menggunakan non probability sampling dengan menggunakan teknik consecutive sampling. Kuesioner menggunakan instrumen A Turkish Version of the Cardiac Patients' Learning Needs Inventory; Patient Questionnaire (TRCPLNI) yang dikembangkan oleh Uysal dan Enç (2012). TR-CPLNI memiliki nilai reabilitas alpha cronbach sebesar 0,916. Uji validitas pada instrumen (TR-CPLNI) telah dilakukan melalui back translation method. Kemudian instrumen pada penelitian ini telah dilakukan uji konten dengan cara melakukan konsultasi kepada ahli bidang. Analisis data hasil penelitian dilakukan dengan menggunakan distribusi frekuensi dan nilai mean dari setiap subvariabel.

Penelitian ini telah melalui uji etik dan mendapatkan persetujuan etik melaui surat Nomor 453/UN6.C.10/PN/2017 dari Komisi Etik Penelitian Kesehatan Fakultas Kedokteran Universitas Padjadjaran Bandung. Seluruh responden yang ikut serta dalam penelitian telah diberikan informed consent dan bersedia untuk mengikuti penelitian.

Tabel 1 Distribusi Frekuensi Karekteristik Responden Klien dengan PJK (n=105)

\begin{tabular}{lcc}
\hline \multicolumn{1}{c}{ Karekteristik Responden } & Frekuensi (f) & Persentase $(\%)$ \\
\hline Usia & 2 & 1.9 \\
18-39 tahun & 61 & 58.1 \\
40-59 tahun & 39 & 37.1 \\
60-74 tahun & 3 & 2.9 \\
75-90 tahun & & \\
Jenis kelamin & 78 & 74.3 \\
Laki-laki & 27 & 25.7 \\
Perempuan & & \\
Pekerjaan & 57 & 54.3 \\
Bekerja & & \\
\hline
\end{tabular}


Rega Dwi Putri : Kajian Kebutuhan Belajar Klien dengan Penyakit Jantung Koroner

\begin{tabular}{lcc}
\hline Tidak Bekerja & 48 & 45.7 \\
Pendidikan & & \\
Tidak Sekolah & 1 & 1 \\
Pendidikan Dasar & 44 & 41.9 \\
Pendidikan Menengah & 33 & 31.4 \\
Pendidikan Tinggi & 27 & 25.7 \\
Agama & & \\
Islam & 98 & 93.3 \\
Kristen & 7 & 6.7 \\
Suku & & \\
Sunda & 84 & 80 \\
Jawa & 13 & 12.4 \\
Lain-lain & 8 & 7.8 \\
\hline
\end{tabular}

Tabel 2 Kebutuhan Belajar Klien dengan Penyakit Jantung Koroner dari Tiap-tiap Subvariabel

\begin{tabular}{lccc}
\hline $\begin{array}{l}\text { Subvariabel Kebutuhan } \\
\text { Belajar Klien dengan } \\
\text { PJK }\end{array}$ & $\begin{array}{c}\text { Jumlah Item } \\
\text { Pernyataan }\end{array}$ & $\begin{array}{c}\text { Mean } \pm \text { SD } \\
\text { (Nilai Rerata) }\end{array}$ & Interpretasi \\
\hline $\begin{array}{l}\text { Kebutuhan tentang } \\
\text { anatomi dan fisiologi } \\
\text { jantung (cara kerja }\end{array}$ & 5 & $4,41 \pm 0,71$ & $\begin{array}{l}\text { Subvariabel dengan } \\
\text { nilai mean tertinggi } \\
\text { mengartikan subvariabel } \\
\text { jantung) }\end{array}$ \\
$\begin{array}{l}\text { Kebutuhan sangat penting atau } \\
\text { sangat dibutuhkan bagi } \\
\text { knformasi obat }\end{array}$ & 5 & $4,34 \pm 0,76$ & \\
$\begin{array}{l}\text { Kebutuhan tentang faktor } \\
\text { gaya hidup }\end{array}$ & 3 & $4,30 \pm 0,77$ & \\
$\begin{array}{l}\text { Kebutuhan tentang } \\
\text { informasi diet }\end{array}$ & 5 & $4,19 \pm 0,82$ & \\
$\begin{array}{l}\text { Kebutuhan tentang } \\
\text { manajemen gejala }\end{array}$ & 6 & $4,08 \pm 0,93$ & \\
$\begin{array}{l}\text { Kebutuhan tentang faktor } \\
\text { psikologis }\end{array}$ & 4 & $4,07 \pm 0,77$ & \\
$\begin{array}{l}\text { Kebutuhan terkait lainnya } \\
\text { Kebutuhan tentang } \\
\text { aktivitas fisik }\end{array}$ & 4 & $3,99 \pm 0,87$ & \\
\hline
\end{tabular}

Tabel 3 Pernyataan dengan Nilai Mean Tertinggi dari Masing-masing Subvariabel Kebutuhan Belajar Klien dengan PJK

\begin{tabular}{|c|c|c|}
\hline $\begin{array}{c}\text { Subvariabel Kebutuhan Belajar } \\
\text { Klien dengan PJK }\end{array}$ & $\begin{array}{l}\text { Pernyataan dengan Nilai Mean } \\
\text { Tertinggi dari Tiap Subvariabel }\end{array}$ & $\begin{array}{c}\text { Mean } \pm \text { SD } \\
\text { (Nilai Rerata Tertinggi dari } \\
\text { Setiap Pernyataan Tiap } \\
\text { Subvariabel) }\end{array}$ \\
\hline $\begin{array}{l}\text { Anatomi dan fisiologi jantung (cara } \\
\text { kerja jantung) }\end{array}$ & $\begin{array}{l}\text { Apa yang dilakukan orang yang } \\
\text { mengalami serangan pada jantung? }\end{array}$ & $4,51 \pm 0,62$ \\
\hline Faktor psikologis & $\begin{array}{l}\text { Apa yang dapat saya lakukan untuk } \\
\text { mengurangi stres dalam hidup } \\
\text { saya? }\end{array}$ & $4,13 \pm 0,73$ \\
\hline Faktor gaya hidup & $\begin{array}{l}\text { Apa yang dapat saya lakukan agar } \\
\text { saya tidak mengalami serangan } \\
\text { pada jantung lagi? }\end{array}$ & $4,44 \pm 0,64$ \\
\hline
\end{tabular}


Rega Dwi Putri : Kajian Kebutuhan Belajar Klien dengan Penyakit Jantung Koroner

\begin{tabular}{lll} 
Informasi obat & $\begin{array}{l}\text { Aturan umum mengenai } \\
\text { penggunaan obat }\end{array}$ & $4,41 \pm 0,71$ \\
Informasi diet & $\begin{array}{l}\text { Aturan umum mengenai pola } \\
\text { makan sehat }\end{array}$ & $4,35 \pm 0,73$ \\
Aktivitas fisik & $\begin{array}{l}\text { Aturan umum mengenai kegiatan } \\
\text { fisik setelah serangan pada jantung }\end{array}$ & $4,26 \pm 0,76$ \\
Manajemen Gejala & $\begin{array}{l}\text { Apa yang dapat saya lakukan saat } \\
\text { nyeri dada? }\end{array}$ & $4,27 \pm 0,76$ \\
Informasi Lainnya & $\begin{array}{l}\text { Dimanakah keluarga saya dapat } \\
\text { memperoleh informasi rinci } \\
\text { mengenai CPR (resusitasi jantung } \\
\text { paru)? }\end{array}$ & $4,31 \pm 0,84$ \\
\hline
\end{tabular}

\section{Hasil Penelitian}

Tabel 1 menunjukkan data karekteristik demografi berdasarkan usia, jenis kelamin, pekerjaan, pendidikan, agama, dan suku. Dilihat dari karekteristik responden, sebagian besar klien PJK berusia dalam rentang 4059 tahun sebanyak 61 responden, berjenis kelamin laki-laki yaitu sebanyak 78 responden, dan klien masih bekerja sebanyak 57 responden. Dilihat dari pendidikan, hampir setengahnya klien berpendidikan dasar sebanyak 44 responden, dan hampir seluruh beragama Islam yaitu sebanyak 98 responden serta bersuku Sunda yaitu sebanyak 84 responden.

Table 2 mendapatkan hasil bahwa sebagian besar kebutuhan belajar klien dengan PJK yang dianggap sangat penting yaitu kebutuhan belajar pada subvariabel anatomi dan fisiologi jantung (cara kerja jantung) dengan nilai mean tertinggi $(4,41)$, dan kebutuhan belajar dengan nilai mean terendah $(3,64)$ yaitu kebutuhan tentang aktivitas fisik.

Tabel 3 menunjukkan bahwa item pernyataan dengan nilai mean tertinggi dari masing-masing subvariabel. Nilai mean mengartikan semakin tinggi nilai mean, maka semakin penting bagi klien. Dari tabel diatas didapatkan nilai mean pernyataan tertinggi dari seluruh subvariabel adalah pernyataan pada subvariabel anatomi fisiologi jantung yaitu pernyataan "Apa yang dilakukan orang yang mengalami serangan pada jantung".

\section{Pembahasan}

PJK memiliki dampak terhadap berbagai aspek kehidupan penderitanya, baik secara fisik maupun psikososial. Secara fisik penderita akan merasakan sesak, mudah lelah, mengalami gangguan seksual, serta nyeri dada, selain itu masalah psikososial seperti cemas dan depresi juga sering dialami oleh klien (Gustad, Laugsand, Janszky, Dalen, \& Bjerkeset, 2014; Lane, Carrol, Lip, Carroll, \& Lip, 2003). Proses pendidikan secara bersama-sama melakukan kegiatan belajar dan mengajar yang hasilnya didefinisikan berupa suatu perubahan perilaku (pengetahuan, keterampilan, dan sikap) akibat paparan terhadap stimulus lingkungan (Bastable \& Susan, 2002). Pembelajaran bertujuan membentuk kesadaran perubahan sikap dan perilaku klien. Perawat harus mengkaji, mengidentifikasi, menentukan, dan mengembangkan metode pembelajaran atau pendidikan dengan menentukan kebutuhan utama yang ingin klien ketahui (Uysal \& Enç, 2012).

Hasil penelitian "Kajian Kebutuhan Belajar Klien dengan Penyakit Jantung Koroner di Salah Satu Rumah Sakit di Kota Bandung" secara keseluruhan kebutuhan belajar yang paling dibutuhkan oleh klien dengan PJK adalah kebutuhan belajar tentang anatomi dan fisologi jantung (cara kerja jantung), kedua tentang informasi obat, ketiga tentang faktor gaya hidup, dan kebutuhan yang menjadi prioritas terendah adalah kebutuhan tentang aktivitas fisik. 
Rega Dwi Putri : Kajian Kebutuhan Belajar Klien dengan Penyakit Jantung Koroner

Kebutuhan anatomi dan fisiologi jantung dianggap paling penting pada penelitian ini. Hal tersebut sejalan dengan hasil penelitian yang dilakukan oleh Uysal dan Enç (2012) di Turki, bahwa informasi mengenai anatomi dan fisiologi juga merupakan kebutuhan yang paling penting bagi klien dalam evaluasi pradischarge. Berbeda dengan hasil penelitian Gerard dan Peterson tahun 1984 dalam Uysal dan Enç (2012), kebutuhan pengetahuan tentang anatomi dan fisiologi ditemukan tidak menjadi kebutuhan paling penting dibandingkan dengan kebutuhan faktor psikologis, faktor risiko, informasi obat, informasi diet, dan aktivitas fisik, justru dalam penelitian Gerard dan Peterson kebutuhan yang paling dibutuhkan adalah tentang faktor gaya hidup. Dalam penelitian yang peneliti lakukan bahwa kebutuhan belajar mengenai anatomi dan fisiologi jantung menjadi sangat penting, namun penelitian sebelumnya tidak penting kemungkinan dipengaruhi oleh faktor pengetahuan. Kebanyakan klien dalam penelitian ini tidak memiliki pengetahuan mengenai informasi anatomi dan fisiologi jantung, tidak menerima informasi yang memadai tentang anatomi fisiologi jantung atau cara kerja jantung. Hal ini diperkuat oleh hasil penelitian Karlik et al. dalam Jaworsky (2005) bahwa kebutuhan anatomi dan fisiologi menjadi penting pada area penelitiannya, karena tidak banyak data tentang anatomi dan patofisiologi PJK yang ditemukan di media. Selain itu, di iklan televisi, sumber internet, dan informasi pamflet yang diberikan kepada pasien hanya sedikit yang mengandung informasi tentang struktur jantung dan apa yang terjadi pada jantung selama serangan. Klien tahu bahwa untuk benar-benar memahami penyakit mereka, maka mereka harus mulai dengan memahami proses penyakit jantung koroner dan kerusakan apa yang telah terjadi pada otot jantung.

Pemahaman yang baik tentang anatomi dan fisiologi PJK ini juga penting untuk mereka memahami bagaimana obat yang diresepkan akan bekerja. Selain itu banyak penelitian lain juga yang menemukan bahwa informasi pengobatan dan faktor gaya hidup merupakan bidang perhatian yang paling penting, bersamaan dengan anatomi dan fisiologi jantung (Jaworski, 2005). Melihat dari hasil penelitian ini, maka perawat dan tenaga medis lainnya dapat memberikan atau lebih menekankan pendidikan kesehatan mengenai anatomi dan fisiologi jantung.

Item pernyataan dengan rerata tertinggi pada subvariabel anatomi dan fisiologi adalah mengenai "Apa yang dilakukan orang yang mengalami serangan pada jantung?". Menurut Henrickson et al. (2004) saat serangan jantung hal yang dapat dilakukan klien adalah klien harus membatasi aktivitas dan harus istirahat karena dapat mengurangi kerja jantung. Bantuan cepat untuk meredakan nyeri dada adalah dengan istirahat dan nitrogliserin. Nitrogliserin dapat mengurangi 50\% lebih intensitas nyeri dada yang diarasakan kurang lebih 5 menit. Widiastuti (2012) dalam penelitiannya menyebutkan bahwa edukasi klien dilakukan dengan tujuan meningkatkan derajat kesehatan klien, mencegah penyakit, dan memperbaiki atau mengembalikan kesehatan.

Subvaribel kebutuhan belajar dengan rerata terendah pada klien PJK pada hasil penelitian ini adalah pada subvaribel tentang kebutuhan aktivitas fisik. Kebutuhan belajar tentang aktivitas fisik menjadi paling rendah, hal ini berkaitan dan dipengaruhi oleh karekteristik responden yang sebagian besar berada pada masa dewasa madya. Menurut teori Hurlock (1980) pada umumnya usia madya atau usia setengah bayi (40-59 tahun) merupakan masa dimana pada masa tersebut ditandai oleh adanya perubahan-perubahan jasmani, terjadi penurunan kekuatan fisik, diiringi pula penurunan daya ingat, dan meningkatnya kecenderungan untuk pensiun. Menurut Erikson, selama usia 40-59 tahun seseorang bisa jadi akan lebih sukses atau sebaliknya mereka berhenti dan tidak mengerjakan sesuatu apapun lagi. Selain itu, pada masa ini terjadi perubahan seksual pada wanita maupun pria, berkaitan dengan item tersebut sebagian besar responden menganggap kehidupan seksual tidak penting lagi serta adanya perubahan minat akibat dari perubahan tugas, tanggung jawab, kesehatan, dan peran dalam hidup. Dalam segi aktivitas banyak orang usia madya khususnya kaum 
Rega Dwi Putri : Kajian Kebutuhan Belajar Klien dengan Penyakit Jantung Koroner

pria secara konstan mungkin menentang atau menolak untuk patuh mengikuti resep dokter tentang diet atau membatasi kegiatan walaupun dengan alasan demi kesehatan (Hurlock, 1980). Hasil penelitian ini mendukung teori tersebut, dimana kebutuhan tentang aktivitas fisik menjadi prioritas terakhir karena sebagian besar responden $(58,1 \%)$ berada pada usia madya yang dapat mempengaruhi klien kurang membutuhkan informasi tentang aktivitas fisik terutama dalam hal kehidupan seksual.

Item pernyataan dengan mean tertinggi pada subvariabel kebutuhan belajar tentang aktivitas fisik adalah pada item mengenai "Aturan umum mengenai kegiatan fisik setelah serangan pada jantung". Menurut Davis (2004) aktivitas fisik adalah multidimensi yang dibuktikan dengan upaya untuk menentukan (frekuensi, durasi, dan intensitas) dalam kaitannya dengan morbiditas, dan mortalitas. Aktivitas fisik telah menunjukkan efektivitas dalam peningkatan rasa kesejahteraan, suasana hati, rasa percaya diri, dan kualitas hidup pada orang dengan penyakit kardiovaskular. Selain itu, menurut Baird (2016) ketika klien keluar dari rumah sakit, penting untuk diketahui klien, bahwa klien harus melanjutkan program aktivitas berupa berjalan kaki yang dimulai secara perlahan dengan catatan tidak melakukan melebihi kemampuan klien. Salah satu tujuan eduaksi klien PJK yaitu klien memiliki semangat hidup, kepercayaan diri, kualitas hidup yang baik (Widiastuti, 2012).

Kebutuhan lainnya yang dibutuhkan klien PJK didapatkan item pernyataan dengan rerata tertinggi mengenai "Dimanakah keluarga saya dapat memperoleh informasi rinci mengenai CPR (resusitasi jantung paru)?". Kebutuhan lainnya yang dibutuhkan klien pada penelitian ini tentang informasi CPR, kemungkinan besar karena kekhawatiran klien terkait pengalaman yang pernah mereka alami terutama saat terjadi serangan pada diri sendiri ataupun berdasarkan kejadian di sekitar. Kebutuhan mengenai informasi CPR (Cardiopulmonary Resuscitation) bagi keluarga klien memang belum didapatkan, maka perlu bagi perawat dan tenaga medis lainnya agar merencankan pembelajaran dan pelatihan untuk keluarga agar belajar bagaimana melakukan CPR. Hal ini bertujuan agar keluarga klien dapat memberikan bantuan dan penanganan langsung terhadap klien saat situasi darurat, serta meminimalisir risiko kematian lebih cepat. Hal yang bisa diberikan rumah sakit adalah dengan mengadakan simulasi penatalaksanaan CPR bagi keluarga klien.

Kebutuhan tiap individu dipengaruhi oleh jenis kelamin, usia, dan tingkat pendidikan juga memengaruhi tingkat tersebut (You et al., 2014). Penelitian sebelumnya telah menunjukkan bahwa pendidikan untuk klien PJK memengaruhi kebutuhan belajar mereka serta dapat meningkatkan pengetahuan mereka tentang penyakit dan meningkatkan kesehatan mereka setelah serangan (You et al., 2014). Berdasarkan teori, jenis kelamin memengaruhi kebutuhan belajar seseorang. Hasil penelitian menyebutkan bahwa kebutuhan belajar pada laki-laki lebih dominan pada kebutuhan aktivitas fisik terkait pekerjaan mereka ingin mengetahui kapan mereka dapat kembali bekerja setelah serangan, dan dalam segi aktivitas seksual. Akan tetapi bila dilihat dari kebutuhan prioritas pada wanita informasi diet menjadi kebutuhan yang paling terpenting bagi mereka, hal ini kemungkinan mereka lebih mementingkan perencanaan dan penyesuaian dirumah setelah keluar dari rumah sakit (Jaworski, 2005). Namun, hal tersebut berbeda dengan hasil penelitian ini, walaupun responden penelitian ini sebagian besar berjenis kelamin laki-laki namun kebutuhan tentang aktivitas fisik justru menjadi kebutuhan yang paling rendah. Peneliti menyimpulkan perbedaan prioritas hasil penelitian ini, kemungkinan juga dipengaruhi oleh perbedaan karekteristik responden di negara tersebut dengan karakteristik responden pada penelitian ini. Kemungkinan diluar negeri dalam rentang usia madya masih sangat produktif. Sehingga mereka memikirkan bagaimana agar dapat kembali bekerja.

\section{Simpulan}

Hasil penelitian mengenai kajian kebutuhan belajar klien dengan Penyakit Jantung 
Rega Dwi Putri : Kajian Kebutuhan Belajar Klien dengan Penyakit Jantung Koroner

Koroner di Salah Satu Rumah Sakit di Kota Bandung dapat ditarik kesimpulan bahwa delapan subvariabel kebutuhan belajar yang diteliti merupakan kebutuhan belajar yang penting menurut pasien PJK. Dari 8 subvariabel tersebut jika diurutkan berdasarkan kebutuhan belajar yang paling penting (mean tertinggi) ke kebutuhan belajar dengan prioritas terendah adalah sebagai berikut: kebutuhan tentang anatomi dan fisiologi jantung; kebutuhan tentang informasi obat; kebutuhan informasi tentang gaya hidup; kebutuhan tentang informasi diet; serta kebutuhan tentang manajemen gejala; kebutuhan belajar tentang faktor psikologi; kebutuhan lainnya; dan kebutuhan tentang aktivitas fisik. Selain itu, informasi lainnya yang paling dibutuhkan klien adalah informasi terkait dimana keluarga klien dapat mempelajari informasi rinci mengenai CPR.

\section{Daftar Pustaka}

Cole, J., Smith, S.M., Hart, N., \& Cupples, M.E. (2011). Systematic review of the effect of diet and exercise lifestyle interventions in the secondary prevention of coronary heart disease. Cardiology Research and Practice, 2011 (Mi), 232351. https://doi. org/10.4061/2011/232351.

Davis, L. (2004). Cardiovascular nursing secrets. United States Of America: Elsevier Mosby.

Delima, M.L., \& Siswoyo, H. (2009). Prevalensi dan faktor determinan penyakit jantung di Indonesia. Bulletin Peneliti Kesehatan, 37(3), 142-159. http://doi. org/10.1017/CBO9781107415324.004.

Galdeano, L.E., \& Rossi, L.A. (2010). Deficient knowledge nursing diagnosis: Identifying the learning needs of patients, 21(3). 618X.2010.01155.

Gustad, L., Laugsand, L., Janszky, I., Dalen, H., \& Bjerkeset, O. (2014). Symptoms of anxiety and depression and risk of acute myocardial infarction: The HUNT 2 study.
European Heart Journal, 35(21), 1394-403. http://doi.org/10.1093/eurheartj/eht387.

Haasenritter, J., Aerts, M., Bosner, S., Buntinx, F., Burnand, B., Herzig, L., ... Donner-Banzhoff, N. (2012). Coronary heart disease in primary care: Accuracy of medical history and physical findings in patients with chest pain--a study protocol for a systematic review with individual patient data. BMC Family Practice, 13, 81. http:// doi.org/10.1186/1471-2296-13-81.

Handayani, S. (2013). Gambaran Tindakan pencegahan sekunder pada klien penyakit jantung koroner, 39-46.

Haryati, R. (2009). Studi deskriftif tentang konstipasi pada klien akut miokard infark di ruang CICU, HCCU, HCU Rumah Sakit Dr. Hasan Sadikin. Bandung, 42.

Henrickson, C.A., Howell, E.E., \& Bush, D.E. (2004). Chest pain relief by nitroglycerin does not predict active coronary artery disease. ACC Current Journal Review, 13(4), 1-7.

Hurlock, E.B. (1980). Psikologi perkembangan suatu pendekatan sepanjang rentang kehidupan. Jakarta: Erlangga.

Ignatavicius, D.D., \& Workman, M. (2013). Medical surgical nursing patient-centered collaborative care. America: Elsevier Saunders.

Indrawati, L. (2012). Analisis faktor yang berhubungan dengan kemampuan pasien PJK melakukan pencegahan sekunder faktor risiko di RSPAD Gatot Soebroto Jakarta. Jakarta: Universitas Indonesia.

Lane, D., Carrol, D., Lip, G.Y.H.H., Carroll, D., \& Lip, G.Y.H.H. (2003). Anxiety, depression, and prognosis after myocardial infarction. Journal of the American College of Cardiology, 42(10), 1808-1810. http://doi. org/10.1016/j.jacc.2003.08.018.

Valiee, S., Razavi, N.S., Aghajani, M., \& Bashiri, Z. (2016). Effectiveness of a psychoeducation program on the quality of 
Rega Dwi Putri : Kajian Kebutuhan Belajar Klien dengan Penyakit Jantung Koroner

life in patients with coronary heart disease: A clinical trial. Applied Nursing Research, 33, 36-41. http://doi.org/10.1016/j. apnr.2016.09.002.

Wahyuni, A., Nurrachmah, E., \& Gayatri, D. (2012). Kesiapan pulang pasien penyakit jantung koroner melalui penerapan. Jurnal
Keperawatan Indonesia, 15(3), 151-158.

You, G.-Y., Li, X., Xu, Y., Hu, X.-L., He, L., Wang, Y.-L., ... Zhang, Q. (2014). Learning needs of Chinese patients before undergoing elective percutaneous coronary intervention. Contemporary Nurse, 47(1-2), 152-8. http:// doi.org/10.5172/conu.2014.47.1-2.152. 